\title{
Comparison of hot water and methanol extraction combined with ultrasonic pretreatment on antioxidant properties of two pigmented rice cultivars
}

\author{
${ }^{1}$ Tobgay, U., ${ }^{1, *}$ Boonyanuphong, P. and ${ }^{2}$ Meunprasertdee, P. \\ ${ }^{I}$ Department of Food Sciences and Nutrition, Faculty of Science and Technology, Prince of Songkla \\ University Pattani Campus, 94000 Thailand \\ ${ }^{2}$ Instrument Center, Faculty of Science and Technology, Prince of Songkla University, Pattani Campus, \\ 94000, Thailand
}

\begin{abstract}
Article history:
Received: 30 September 2019

Received in revised form: 14

November 2019

Accepted: 14 November 2019

Available Online: 11

December 2019
\end{abstract}

Keywords:

Ultrasonic,

Antioxidant,

Pigmented rice

DOI:

https://doi.org/10.26656/fr.2017.4(2).330

\section{Abstract}

Pigmented rice is considered as the good source of phytochemicals which contains more phenolic contents and higher antioxidant activities compared with non-pigmented rice. However, those phytochemicals are normally extracted using inorganic solvent, using water was rarely found. This study was aimed to compare extraction methods on antioxidant contents and activities of two types of Thai pigmented rice (black glutinous rice and red non-glutinous rice). Pigmented rice was extracted either conventional method alone or a combination of ultrasonic plus conventional method with different solvents (methanol and hot water). Phenolic contents were analyzed by spectrophotometric assay and high-performance liquid chromatography (HPLC). Antioxidant activities were investigated by radical scavenging capacity (ABTS and DPPH). The results showed that ultrasonic pretreatment significantly enhanced the total phenolic, flavonoid, anthocyanin contents and higher antioxidant activities compared with conventional extraction irrespective of solvents and rice varieties. Ultrasonic methanol (UM) extraction proved to extract significant higher content of all the compounds analyzed in both the rice varieties. In contrast, hot water (HW) extracts exhibited the lowest amount of bioactive compounds. However, there was no significant difference between methanol extraction alone and ultrasonic pretreatment with hot water extract on antioxidant contents for black glutinous rice. The contents of individual anthocyanins and flavonoids (cyanidin 3-O-glucoside, peonidin 3-O-glucoside, and quercetin) were significantly increased with ultrasonic pretreatment compare to the conventional method in black glutinous rice while failed to detect the red rice variety. The black glutinous rice contained significantly higher contents of all analyzed compounds and antioxidant activities than red rice. In conclusions, our results demonstrated that ultrasonic pretreatment significantly enhanced antioxidant extraction with higher activities compared with conventional extraction irrespective of solvents and rice varieties. Furthermore, the efficiency of ultrasonic together with hot water extraction was almost equal to methanol extraction which was the one effective solvent for extracting antioxidant.

\section{Introduction}

Rice is considered as the good source of phytochemicals including phenolic acids, flavonoids, anthocyanins, proanthocyanidins, tocopherols, tocotrienols, $\gamma$-oryzanol, and phytic acid (Goufo and Trindade, 2014). Previous research has shown that pigmented rice contains higher phenolic content and antioxidant activities, along with greater varieties of health-promoting phytochemicals compared with nonpigmented rice (Chakuton et al., 2012). Especially the black rice is well known to be rich in anthocyanin (Hou et al., 2013), it contains Cyaniding 3-O-glucoside, peonidin 3-O-glucoside, malvidin 3-O-glucoside, pelagonidin 3-O-glucoside and delphinidin 3-Oglucoside (Park et al., 2008). While the major flavonoid pigments in red rice were identified as procyanidins. Anthocyanin possesses strong radical scavenging activities, anti-inflammatory effects and anticarcinogenic properties (Wang et al., 2007; Radovanović and Radovanović, 2010). In addition, it has been reported that the composition of phenolic compounds is noticeably different between glutinous and non-glutinous rice grains. Notably, in non-pigmented rice, total 
phenolic in non-glutinous rice was higher than the glutinous variety.

There are several factors that affect the yield of antioxidant compounds during the extraction process. For example, solvent and extraction method used during the process. The extraction of phenolics from plant materials was often with different solvents, such as methanol, ethanol, acetone, ethyl acetate, and their combinations (Dai and Mumper, 2010). Arab et al. (2011) reported that methanol showed significant greater yield and antioxidant activities compare with ethanol and ethyl acetate. Even though methanol is the most common and effective solvent for extracting polyphenols, it is more toxic and considered as environmental pollutant than other types of alcohol (Kapasakalidis et al., 2006). Furthermore, the extraction of phenolic compounds from plant materials is also influenced by the extraction protocols, which obviously have effects over the yield and antioxidant activities. In this context, due to the ineffective conventional extraction processes, it gave rise to the development of new efficient extraction techniques like ultrasonic-assisted extraction. Ultrasonic assisted extraction (UAE) involves the application of high-intensity, high-frequency sound waves and their interaction with materials. UAE is a useful technology that does not require any complex instruments and is relatively low-cost. It can be used both on a small and large scale. In most studies, phenolic compounds from pigmented rice were extracted by various solvents such as methanol, ethanol, acetone and ethyl acetate, using water as a solvent was rare. Therefore, the present study was aimed to compare extraction methods on phytochemical contents and their antioxidant capacity from Thai pigmented rice by either conventional method alone or combination of the ultrasonic plus conventional method with different solvents (methanol and hot water).

\section{Materials and methods}

\subsection{Plant material}

Black glutinous rice (Neaw dum moa37) and Red non-glutinous rice (Hom gradung-nga57) were obtained from Pattani rice research center. All rice grains were dehusked with the NW 2000 Turbo machine and removed the deformed grains manually after de-husking. All samples were stored immediately at $-20^{\circ} \mathrm{C}$ until analysis.

\subsection{Extraction methods}

There are four extraction methods (1) Hot Water Extraction (HW) rice grains $(20 \mathrm{~g})$ were extracted with water $(100 \mathrm{~mL})$ for $10 \mathrm{mins}$ at $100^{\circ} \mathrm{C}$. The extract was filtered with nylon cloth and centrifuged at $8,000 \mathrm{rpm}$ for 15 mins to obtain clear supernatant. (2) Methanol extraction (M) methanol extraction was carried out according to Choi et al. (2007) with slight modification. The $20 \mathrm{~g}$ rice was extracted with $100 \mathrm{~mL}$ of $80 \%$ methanol in water at room temperature for $24 \mathrm{hr}$ followed by removing the grain remaining from the extract using nylon cloth and centrifuging at $8,000 \mathrm{rpm}$ for 15 mins. (3) Ultrasonic pretreatment followed by hot water extraction (UHW) and (4) methanol extraction (UM) sample was carried out pretreatment with ultrasonic probe for 40 mins, $20 \mathrm{kHz}$ and $40 \%$ amplitude with temperature not exceeding $35^{\circ} \mathrm{C}$. Then, the extract was extracted as described in hot water and methanol extraction respectively.

\subsection{Analysis of antioxidant contents}

\subsubsection{Determination of total phenolic contents (TPC)}

Folin-Ciocalteau reagent was diluted with water 1:9 $(\mathrm{v} / \mathrm{v})$. Then $60 \mu \mathrm{L}$ of the sample $(1 \mathrm{mg} / \mathrm{mL})$ was added to $2.5 \mathrm{~mL}$ of this freshly prepared reagent. The solution was incubated for 2 mins at room temperature and $2 \mathrm{~mL}$ of sodium carbonate $(75 \mathrm{~g} / \mathrm{L})$ was subsequently added to the solution. Then, the mixture was incubated for 15 mins at $50^{\circ} \mathrm{C}$ and cooled with ice-water bath. The absorbance was measured at $760 \mathrm{~nm}$ within 15 mins. The results were expressed as $\mathrm{mg}$ gallic acid equivalent (GAE)/100 g grain.

\subsubsection{Determination of total flavonoid contents (TFC)}

The total flavonoid content was determined according to Zhishen et al. (1999) with slight modification. A total of $250 \mu \mathrm{L}$ of extract $(1 \mathrm{mg} / \mathrm{mL})$ was transferred into a test tube and the mixture of 1.25 $\mathrm{mL}$ of distilled water and $75 \mu \mathrm{L}$ of $5 \% \mathrm{NaNO}_{2}$ was added and incubated for 5 mins. After the incubation period, $150 \mu \mathrm{L}$ of $10 \%$ of $\mathrm{AlCl}_{3}$ and $1 \mathrm{~mL}$ of $\mathrm{NaOH}$ was then added respectively. When the reaction was completed, the absorbance was measured at $510 \mathrm{~nm}$ by using a spectrophotometer. The flavonoid content was determined by using quercetin standard and expressed as $\mathrm{mg}$ quercetin $/ 100 \mathrm{~g}$ rice grain.

\subsubsection{Determination of total anthocyanin contents (TAC)}

The $400 \mu \mathrm{L}$ of the sample $(1 \mathrm{mg} / \mathrm{ml})$ was diluted with the buffer $(0.025 \mathrm{mM} \mathrm{KCl})$ at $\mathrm{pH} 1.0$ and incubated for 15 mins at room temperature before the first measurement. For the second measurement, the sample was diluted with the buffer $\mathrm{pH} \quad 4.5 \quad(0.4 \quad \mathrm{mM}$ $\mathrm{CH}_{3} \mathrm{COONa}$ ) and incubated in the dark for 5 mins for the repeated measurement. The absorbance readings were measured against water as a blank. The concentration of Total Anthocyanin (TA) content was calculated in terms of cyanidin-3-glucoside using the following equation: 
Anthocyanin contents $(\mathrm{mg} / \mathrm{liter})=(\mathrm{A} \times \mathrm{MW} \times \mathrm{DF} \times$ $1000) /(\mathrm{e} \times 1)$.

Where $\mathrm{A}=(\lambda 500 \mathrm{~nm}-\lambda 700 \mathrm{~nm}) \mathrm{pH} 1.0-(\lambda 500 \mathrm{~nm}-\lambda$ $700 \mathrm{~nm}) \mathrm{pH} 4.5 ; \mathrm{MW}=$ (molecular weight $)=449.2 \mathrm{~g} /$ mole for cyanidin-3-glucoside; $\mathrm{DF}=$ dilution factor; and $\mathrm{e}=26900$ molar extinction coefficient.

\subsection{Analysis of antioxidant activities}

\subsubsection{Determination of DPPH}

The assay was carried out according to the method of Butsat and Siriamornpun (2010). The DPPH radical was prepared by dissolving $0.0039 \mathrm{~g}$ of DPPH powder in the $50 \mathrm{~mL}$ of ethanol. A total of $3 \mathrm{~mL}$ of DPPH solution was added to $3 \mathrm{~mL}$ of rice extract $(1 \mathrm{mg} / \mathrm{mL})$ and kept in the dark at room temperature for 30 mins. The absorbance was measured at $517 \mathrm{~nm}$ relative to the control. The $\mathrm{DPPH}^{*}$ solution without the added sample was measured for its absorbance as the control. The DPPH scavenging activity (\%) of samples was expressed as DPPH\% $=(1-$ A sample/A control) x 100\%).

\subsubsection{Determination of ABTS}

The assay was carried out according to Choi et al. (2007). The ABTS radical cation reagent (stock solution) was prepared by adding $7 \mathrm{mM}$ ABTS in ethanol with potassium persulphate $\left(\mathrm{K}_{2} \mathrm{~S}_{2} \mathrm{O}_{8}\right)$ solution to obtain the concentration of $2.45 \mathrm{mM}$ and kept it in the dark for 12 $14 \mathrm{hr}$ at room temperature. The ABTS radical cation reagent was diluted to obtain the absorbance of 1.2-1.4 at $414 \mathrm{~nm}$ by adding distilled water. An aliquot $(1 \mathrm{~mL})$ of ABTS diluted reagent was added to $200 \mu \mathrm{L}$ of extracts (1 $\mathrm{mg} / \mathrm{mL}$ ) and measured the absorbance at $414 \mathrm{~nm}$ after incubating in the dark against water blank after $1 \mathrm{hr}$.

\subsection{HPLC analysis}

Analysis of anthocyanin and flavonoid content was carried by using high-performance liquid chromatography (HPLC). Four samples were obtained from various extraction methods subsequently concentrated individually by using rotatory evaporator to reach the concentration of $1000 \mathrm{mg} / \mathrm{mL}$.

\subsubsection{Identification and quantification anthocyanins}

The anthocyanin profile was determined by using HPLC (Agilent 1100 series, DAD-FLD) according to Kim et al. (2010). Anthocyanin was separated on a C18 column $(250 \times 4.6 \mathrm{~mm}, 5 \mu \mathrm{m}$, Luna, phenomenex) by HPLC. Elution was performed using a binary gradient of $0.1 \%$ formic acid in water (mobile phase A) and $0.1 \%$ formic acid in acetonitrile (mobile phase $\mathrm{B}$ ) according to, $0 \mathrm{~min}, 95 \% \mathrm{~A} / 5 \% \mathrm{~B} ; 40 \mathrm{~min}, 50 \% \mathrm{~A} / 50 \% \mathrm{~B} ; 42 \mathrm{~min}, 0 \%$ $\mathrm{A} / 100 \% \mathrm{~B} ; 52 \min , 0 \% \mathrm{~A} / 100 \% \mathrm{~B} ; 54 \mathrm{~min}, 95 \% \mathrm{~A} / 5 \%$
$\mathrm{B}$; and $64 \mathrm{~min}, 95 \% \mathrm{~A} / 5 \% \mathrm{~B}$. The flow rate was $1.0 \mathrm{~mL} /$ min, and the column temperature was $30^{\circ} \mathrm{C}$. The UV-vis detector wavelength was set at $520 \mathrm{~nm}$. Anthocyanin (cyanidin-3-glucoside (Cy-3G) and peonidin-3glucoside $(\mathrm{Pe}-3-\mathrm{G})$ ) were used as standards to identify the compounds in the sample.

\subsubsection{Identification and quantification of flavonoids}

Determination of the flavonoid was performed according to the method of Kim et al. (2010). Flavonoid aglycones contained in rice extract were separated on a C18 column $(250 \times 4.6 \mathrm{~mm}, 5 \mu \mathrm{m}$, $)$ by HPLC equipped with a photodiode array (PDA) detector. The elution was performed using a binary gradient of $0.1 \%$ formic acid in water (mobile phase A) and $0.1 \%$ formic acid in acetonitrile (mobile phase B) according to the following gradient: $0 \mathrm{~min}, 95 \% \mathrm{~A} / 5 \% \mathrm{~B} ; 30 \mathrm{~min}, 60 \% \mathrm{~A} / 40 \% \mathrm{~B}$; $45 \mathrm{~min}, 50 \% \mathrm{~A} / 50 \% \mathrm{~B} ; 50 \mathrm{~min}, 0 \% \mathrm{~A} / 100 \% \mathrm{~B} ; 60 \mathrm{~min}$, $0 \% \mathrm{~A} / 100 \% \mathrm{~B} ; 62 \mathrm{~min}, 95 \% \mathrm{~A} / 5 \% \mathrm{~B}$; and $70 \mathrm{~min}, 95 \%$ $\mathrm{A} / 5 \% \mathrm{~B}$. The flow rate was $1.0 \mathrm{~mL} / \mathrm{min}$ and the column temperature was $40^{\circ} \mathrm{C}$. The ultraviolet-visible (UV-vis) detector wavelength was set at $364 \mathrm{~nm}$. Flavonoid (Quercetin and Apigenin) were used as standards to identify the compounds in the sample.

\subsection{Statistical analysis}

All determinations were carried out in triplicate, and data were subjected to analysis of variance (ANOVA), using the statistical package SPSS, Version 17. Significant differences between means were determined by Duncan's multiple range tests. $P$ values less than 0.05 were considered statistically significant.

\section{Results and discussion}

\section{1 antioxidant contents}

\subsubsection{Total phenolic contents (TPC)}

TPC from four extraction methods, the results showed that the total phenolic contents for black glutinous rice ranged from 419.56 to $568.25 \mathrm{mg}$ GAE/100 g grains which were higher than red rice 248.75 - $433 \mathrm{mg}$ GAE/100 g grains (Table 1). The methods with ultrasonic pretreatment significantly $(\mathrm{P}<0.05)$ increased total phenolic contents compared to HW and $\mathrm{M}$ extraction alone. The ultrasonic pretreatment on HW and $\mathrm{M}$ extraction increased the phenolic content by $7.4 \%$ and $18.9 \%$ in black glutinous rice and $25 \%$ and $18.9 \%$ in red rice. This is due to the fact that during ultrasonic treatment, ultrasonic waves increase the interaction between the molecules in the sample breaking down the cell wall and releasing the bioactive compounds (Hossain et al., 2012). Similarly, Chooklin (2014) evaluated the optimum ultrasound-assisted extraction condition of brown rice extract and found that 
Table 1. Effect of extraction methods on total antioxidant contents of black glutinous rice and red rice

\begin{tabular}{cccc}
\hline $\begin{array}{c}\text { Rice varieties/ extraction } \\
\text { methods }\end{array}$ & $\begin{array}{c}\text { TPC } \\
\text { (mg GAE/100 g sample) }\end{array}$ & $\begin{array}{c}\text { TFC } \\
\text { (mg quercetin/100 g sample) }\end{array}$ & $\begin{array}{c}\text { TAC } \\
\text { (mg Cy-3-G/100 g sample) }\end{array}$ \\
\hline Black glutinous rice & & & \\
\hline HW & $419.56 \pm 16.93^{\mathrm{cA}}$ & $1631.58 \pm 45.43^{\mathrm{cA}}$ & $214.26 \pm 11.32^{\mathrm{dA}}$ \\
M & $460.39 \pm 26.64^{\mathrm{bA}}$ & $1966.66 \pm 43.97^{\mathrm{bA}}$ & $293.76 \pm 11.63^{\mathrm{bA}}$ \\
UHW & $452.81 \pm 12.16^{\mathrm{bA}}$ & $2003.87 \pm 74.36^{\mathrm{bA}}$ & $237.77 \pm 10.30^{\mathrm{cA}}$ \\
UM & $568.25 \pm 16.06^{\mathrm{aA}}$ & $2534.08 \pm 23.67^{\mathrm{aA}}$ & $358.68 \pm 5.35^{\mathrm{aA}}$ \\
\hline Red rice & & & $1.17 \pm 0.25^{\mathrm{dB}}$ \\
\hline & $248.75 \pm 9.28^{\mathrm{dB}}$ & $855.07 \pm 51.87^{\mathrm{dB}}$ & $1.90 \pm 0.31^{\mathrm{cB}}$ \\
HW & $321.60 \pm 7.11^{\mathrm{cB}}$ & $1137.42 \pm 37.47^{\mathrm{cB}}$ & $2.58 \pm 0.41^{\mathrm{bB}}$ \\
UH & $332.39 \pm 6.38^{\mathrm{bB}}$ & $1282.87 \pm 30.29^{\mathrm{bB}}$ & $4.82 \pm 0.39^{\mathrm{aB}}$ \\
\hline
\end{tabular}

Values are means \pm SD. Values with different superscript ${ }^{\text {a-d }}$ (lower case) letters within the same column are significantly different $(\mathrm{P}<0.05)$. Values with ${ }^{\mathrm{A}-\mathrm{B}}$ different superscript (upper case letters) between rice are significantly different $(\mathrm{P}<0.05)$ respectively. HW: hot water, M: methanol, UM: ultrasonic+methanol, UHW: ultrasonic+hot water

the total phenolic content obtained by ultrasound-assisted extraction was higher than conventional extraction method by $15.31 \%$. In addition, ultrasonic treatment prior to methanol extraction (UM) extract the highest TPC of the black glutinous rice $(568.25 \pm 16.06 \mathrm{mg}$ GAE/100 g grain) which was significantly higher $(\mathrm{P}<0.05)$ than other three extraction methods. The similar trend in TPC was observed in red rice variety where the samples were pre-treated with ultrasonic prior methanol extraction $(433.61 \pm 12.89 \mathrm{mg}$ GAE/100 g sample). The quantity TPC of the black glutinous rice and red rice by different extraction methods was $\mathrm{UM}>\mathrm{M}=\mathrm{UHW}>\mathrm{HW} \quad$ and $\mathrm{UM}>\mathrm{UHW}>\mathrm{M}>\mathrm{HW}$ respectively. However, there was no significant difference between $\mathrm{M}$ extraction and UHW for black glutinous rice. It is possible that the efficiency of extraction solvent was also involved. Paniwnyk et al. (2001) reported that, especially in methanol, hydrogen peroxide and large proportions of free radicals are not formed while exposed to sonication, unlike in water that induces phenolic degradations. The ultrasound-assisted the extraction by improving the efficacy of this methodology. When compared with multiple solvents for the extraction of five isoflavone from Iris tectorum, methanol gave the highest extraction yield, followed by water and ethanol due to differences in the polarities and viscosities (Sun et al., 2011). In another study, methanolic extract of colored and non-colored Thai rice cultivars yielded higher phenolic content than distilled water, hexane and ethyl acetate extract (Chakuton et al., 2012). Usually the plant materials contain different quantities of phenolic acids, phenylpropanoids, anthocyanins and tannins and many others compounds. The chances of phenolic interaction with other plant components such as carbohydrates and proteins may lead to the formation of insoluble complexes. Therefore, the solubility of phenolic is affected by the polarity of solvent used in the extraction (Naczk and Shahidi, 2006). Though the polarity of the water is higher than the organic solvents, the polyphenols are mostly soluble in less polar organic solvents suggesting that the polar properties of the polyphenol determine its solubility (Kim and Lee, 2005). Additionally, during the ultrasonic extraction, the solvent properties affect the formation of the cavitation bubbles and cavitation is one of the main mechanisms by which ultrasound can improve extraction efficiency. Its efficiency depends on the collapse of cavitation bubbles which produces microjets that disrupt plant cell membrane and provoking the release of bioactive compounds. The formation of the cavitation bubbles is affected by the surface tension of the solvents used in the extraction. The cavitation bubbles are formed easily in liquids with lower surface tension compared to higher surface tension because the ultrasonic energy can easily overcome the surface tension forming cavitation bubbles more easily (Ghasemzadeh et al., 2015). Aqueous methanol has comparatively lower surface tension compared to the water, which enabled to extract significantly higher content of flavonoids in our study.

\subsubsection{Total flavonoid contents (TFC)}

The present study, TFC from four extraction methods was in the range of $1631.58-2534.08 \mathrm{mg}$ quercetin equivalent $/ 100 \mathrm{~g}$ for the black glutinous rice and $855.07-1798.19 \mathrm{mg}$ quercetin equivalent $/ 100 \mathrm{~g}$ for the red rice (Table 1). Among four extraction methods, TFC extracted by each method had similar trend to total phenolic content. The flavonoid content of black glutinous rice and red rice extracted by ultrasonic pretreatment were significantly $(\mathrm{P}<0.05)$ increased by $18.62 \%, 22.3 \%$, and $33.3 \%, 36.7 \%$ compared to HW and $\mathrm{M}$ extraction alone. The total flavonoid content of the black glutinous rice and red rice by difference extraction methods was $\mathrm{UM}>\mathrm{M}=\mathrm{UHW}>\mathrm{HW}$ and $\mathrm{UM}>\mathrm{UHW}>\mathrm{M}>\mathrm{HW}$ respectively. This result indicates that flavonoid extraction was enhanced by the ultrasonic treatment. In addition, ultrasonic pretreatment prior methanol extraction showed the highest content of total flavonoid with the value of $2534.08 \mathrm{mg}$ quercetin 
equivalent/100 g sample compared to the other three methods. Sun et al. (2011) reported out of three different extraction methods, ultrasonic extraction gave the highest extraction yield of flavonoids such as- tectoridin, iristectorin B, iristectorin A, tectorigenin, iristectorigenin $\mathrm{A}$, and total isoflavones in lesser time compared to maceration and Soxhlet extraction. Therefore, ultrasonic extraction can be a potential extraction procedure to extract plant flavonoids. Paniwnyk et al. (2001) also reported, the extraction of rutin from the Sophora Japonica was improved by ultrasonic treatment $(20 \mathrm{KHz}, 27 \mathrm{~W})$ carried out at room temperature compared to conventional methods (boiling and reflux) using same solvents (diluted aqueous alkali and methanol). However, the efficiency was dependent on the solvent type, where the application of the ultrasonic on methanol extraction significantly increased the yield unlike ultrasonic treatment on aqueous solvent.

\subsubsection{Total anthocyanin contents (TAC)}

Anthocyanin content for black glutinous rice was in the range of 214.26-358.68 mg Cyaniding 3-O-glucoside equivalents/100 g sample and 1.17- 4.82 cyanidin 3-Oglucoside equivalents/100 g sample for red rice. The combination of ultrasonic and solvent extraction resulted in increased TAC compared to solvent extraction alone in both rice varieties. This trend was similar to TPC and TFC obtained from ultrasonic pretreatment. Black glutinous rice extracted by ultrasonic treatment with methanol had highest anthocyanin content of $358.68 \pm 5.35 \mathrm{mg}$ of $\mathrm{Cy}-3-\mathrm{G} / 100 \mathrm{~g}$ sample and this was significantly higher $(\mathrm{P}<0.05)$ than other treatments within black glutinous rice. Apparently among the red rice varieties, ultrasonic treatment with methanol indicated significantly higher anthocyanin content $4.82 \pm 0.39$ cyanidin 3 -O-glucoside equivalents/100 g sample than other treatments within red rice. The anthocyanin content was increased by $9.9 \%, 18.1 \%$ and $54.7 \%, 60.6 \%$ in black glutinous rice and red rice respectively compared to hot water and methanol extraction alone. As mentioned previously in TPC, this is due to the fact that ultrasonic can rupture the sample matrix releasing intracellular content and facilitating extraction procedure (Santos et al., 2013). In both rice, when compared to UHW and UM, the latter is able to extract higher total anthocyanin contents. Our study result's suggests that ultrasonic pretreatment is not only superior in yielding significantly higher TPC and TFC, but also specifically increases the anthocyanin content compared to the conventional extractions. It can be due to the effect of solvents as mentioned in TPC and TFC scenario. Similarly anthocyanin accessibility can be also strongly dependent on the solvents capacity to enter rice grain structures and their ability to extract. The ultrasonic extraction is directly affected by the ultrasound frequency, intensity and sample characteristics. Sonication frequencies consists of mainly two bands, low power ultrasound (low amplitude and high frequency, $100-1000 \mathrm{kHz}$ ) or high power ultrasound (high amplitude and low frequency, 20-100 kHz) (Golmohamadi et al., 2013). It's been well known that at lower frequency, larger cavitation bubbles are formed. Therefore the lower frequencies of high-power ultrasound (around $20 \mathrm{kHz}$ ) can achieve more violent bubble implosions elevating the extraction efficiency (Esclapez et al., 2011). On the other hand, low intensity ultrasound which uses small power levels with lower frequencies $(5-10 \mathrm{MHz})$ doesn't cause any physical or chemical alterations. It doesn't necessarily mean that high power ultrasonic is suitable in extraction purposes. Suitable power with lower frequencies is better than higher frequencies in extraction yield. Ravanfar et al. (2015) reported when high power ultrasonic is applied, the sound energy is converted into heat causing the anthocyanin degradation. Therefore exposing the materials containing anthocyanin which is very sensitive to temperature ultimately lead to low anthocyanin yield (Chigurupati et al., 2002). The anthocyanin content was relatively lower in red rice varieties as to black glutinous rice. The result showed that the lowest anthocyanin content was exhibited by red rice variety extracted with hot water $(1.17 \pm 0.25$ cyanidin 3-O-glucoside equivalents/100 g samples) amongst all the treatments from two rice varieties. This result has agreed with Abdel-Aal et al. (2006) who also found that anthocyanin content in red rice $(0.094 \mathrm{mg} / \mathrm{g})$ was very much lower than black rice $(3.27 \mathrm{mg} / \mathrm{g})$ when rice was extracted twice by mixing with $24 \mathrm{~mL}$ of methanol acidified with $1.0 \mathrm{~N} \mathrm{HCl}(85: 15, \mathrm{v} / \mathrm{v})$ and shaking at $1800 \mathrm{rpm}$ for 30 mins. Several studies revealed that ultrasonic treatments aided the extraction of phytochemicals, especially anthocyanin like in our case. Santos et al. (2013) reported that ultrasound-assisted extract was more efficient in extracting anthocyanins compared to conventional methods (agitated bed and Soxhlet extraction techniques) from jambul (Syzygium cumini) peels with acidified ethanol as the extraction solvent. In another study, fresh red cabbage (Brassica oleracea L. Var. Capitata F. Rubra) extracted with ultrasonic treatment, anthocyanin content was 2 times greater compared to control extraction procedure performed in a water bath. Similarly, Sivakumar et al. (2009) demonstrated a significant increase in betalains (red coloured cyanins) with ultrasonic extraction from beet root in comparison with the magnet stirrer extraction method. Moreover, Cheok et al. (2013) reported ultrasonic treatment were able to extract total monomeric anthocyanin and total polyphenol content $45.6 \%$ and 
Table 2. Effect of extraction methods on antioxidant activities of black glutinous rice and red rice

\begin{tabular}{ccc}
\hline Rice varieties/ extraction methods & ABTS (\% of scavenging) & DPPH (\% of inhibition) \\
\hline Black glutinous rice & & \\
\hline HW & $51.31 \pm 0.67^{\mathrm{cA}}$ & $63.59 \pm 2.31^{\mathrm{bA}}$ \\
M & $55.52 \pm 0.63^{\mathrm{bA}}$ & $68.57 \pm 2.11^{\mathrm{aA}}$ \\
UHW & $54.64 \pm 1.80^{\mathrm{bA}}$ & $68.22 \pm 1.02^{\mathrm{aA}}$ \\
UM & $65.60 \pm 2.49^{\mathrm{aA}}$ & $69.41 \pm 1.06^{\mathrm{aA}}$ \\
\hline & & \\
\hline Red rice & $46.41 \pm 2.35^{\mathrm{cB}}$ & $47.18 \pm 2.26^{\mathrm{cB}}$ \\
MW & $50.32 \pm 1.34^{\mathrm{bB}}$ & $54.30 \pm 1.58^{\mathrm{bB}}$ \\
UHW & $51.51 \pm 1.78^{\mathrm{bB}}$ & $55.61 \pm 1.44^{\mathrm{bB}}$ \\
UM & $61.19 \pm 1.44^{\mathrm{aB}}$ & $65.60 \pm 3.63^{\mathrm{aB}}$ \\
\hline
\end{tabular}

Values are means \pm SD.Values with different superscript ${ }^{\mathrm{a}-\mathrm{c}}$ (lower case) letters within the same column are significantly different $(\mathrm{P}<0.05)$. Values with ${ }^{\mathrm{A}-\mathrm{B}}$ different superscript (upper case letters) between rice are significantly different $(\mathrm{P}<0.05$ ) respectively. HW: hot water, M: methanol, UM: ultrasonic+methanol, UHW: ultrasonic+hot water

$8.8 \%$ higher $(\mathrm{P}<0.05)$ compared to untreated ones (extracted with magnetic stir for $1 \mathrm{hr}$ at room temperature) from mangosteen hull.

\subsection{Antioxidant activities}

The antioxidant activities (DPPH and ABTS) of two rice extracts obtained through different extraction methods were shown in Table 2. Significant differences $(\mathrm{P}<0.05)$ in antioxidant activities were observed in ultrasonic pretreatment methods in comparison to solvent extraction alone. Ultrasonic pretreatment increased scavenging activity of both rice extracts. This might be due to increase of TPC and TFC in the extract with ultrasonic treatment. Goffman and Bergman (2004) stated the antioxidant properties are directly correlated to the TPC. The phenolic content had a strong positive correlation with the flavonoid content and antioxidant capacity, in agreement with Shen et al. (2009). Especially the UM had higher antioxidant activities, followed by $\mathrm{UHW}>\mathrm{M}>\mathrm{HW}$ extraction in both the rice varieties. Representing rice extracts with higher phenolic content, flavonoid content simultaneously had higher antioxidant activities marking the significance of ultrasonic treatment.

\subsection{HPLC analysis}

3.3.1 Effect of extraction methods on the contents of individual anthocyanins

Anthocyanin level (Cyanidin-3-glucoside (Cy-3G) and peonidin-3- glucoside (Pe-3-G)) extracted from four extraction procedures were presented in Table 3 . Chromatogram of standard was shown in Figure 1. The results show two different anthocyanins were detected in all black glutinous rice extracted with four different extraction procedures. Except in red rice variety, Cy-3G and Pe-3-G were not detected. The content of individual anthocyanins depends on extraction method, where ultrasonic pretreatment was more effective than solvent extraction alone. The trend of these compounds obtained from different extraction methods analyzed by HPLC was parallel to TPC analyzed by spectrophotometer. In addition, the black glutinous rice extracted with UM contained significantly higher $(\mathrm{P}<0.05)$ content of $\mathrm{Cy}-3 \mathrm{G}$ and $\mathrm{Pe}-3-\mathrm{G}$ as to other extraction procedures. Cy-3G content was $24.58 \%, 24.63 \%$ and $54.85 \%$ higher than $\mathrm{M}$, UHW and HW extracts respectively. Even in terms of Pe -3-G contents, UM was significantly higher compared to other treatments $(26.1 \%, 25.1 \%$ and $59.6 \%$ higher than M, UHW and HW extract respectively). It was consistent with previous study report (Kim et al., 2008), where three varieties of rice (black, red and wild rice) were evaluated for their anthocyanin profile and its nutritive potential. In which acidic methanol extracts of the black and wild rice marked the presence of three different pigments by HPLC analysis, characterized on the basis of UV-Vis/MS properties and the retention times of components separated by LC. While those pigments were not detected in acidic methanol extract of the red rice, out of three pigments detected, only two pigments were identified, Cyaniding-3-glucoside as the major anthocyanin and Cyaniding-fructoside. Similarly, Pengkumsri et al. (2015) also reported the red rice tested (Mali red rice) did not show any trace of anthocyanins. However, Laokuldilok et al. (2011) reported all the pigmented rice varieties contained both $\mathrm{Cy}-3 \mathrm{G}$ and Pe-3$\mathrm{G}$ except in normal rice brans, but $\mathrm{Cy}-3 \mathrm{G}$ and $\mathrm{Pe}-3-\mathrm{G}$ contents were relatively low in red rice brans $(179.0 \pm 7.7$ and 9.1 $\pm 1.4 \mu \mathrm{g} / \mathrm{g}$ respectively). Similarly, Abdel-Aal et al. (2006) demonstrated even red rice varieties contained very low content of Cyanidin-3-glucoside $(14.0 \pm 0.3 \mu \mathrm{g} /$ g) and Peonidin-3-glucoside $(2.5 \pm 0.1 \mu \mathrm{g} / \mathrm{g})$ in red rice. Furthermore, $\mathrm{pH}$, temperature, glycosidic linkages and food matrix interactions that occurs during cooking process influences the stability of the anthocyanins. Notably, thermal in the present study, the anthocyanins obtained from hot water (HW) extraction yielding the significantly lower anthocyanins contents compared to 
Table 3. Effect of extraction methods on content of Cyaniding-3-glucoside (Cy-3-G) and peonidin-3-glucoside (Pe-3-G) and their ratios of black glutinous rice

\begin{tabular}{ccccc}
\hline \multirow{2}{*}{ Treatment } & \multicolumn{4}{c}{ Anthocyanin (mg/100g grain) } \\
\cline { 2 - 5 } & Cy-3G & Pe-3-G & Total & Cy3G:Pe3G \\
\hline HW & $89.00 \pm 3.73^{\mathrm{c}}$ & $40.89 \pm 4.66^{\mathrm{c}}$ & 129.89 & $69: 31: 00$ \\
M & $184.78 \pm 4.42^{\mathrm{b}}$ & $94.67 \pm 9.80^{\mathrm{b}}$ & 279.45 & $66: 34: 00$ \\
UHW & $184.58 \pm 8.02^{\mathrm{b}}$ & $96.65 \pm 7.85^{\mathrm{b}}$ & 281.23 & $66: 34: 00$ \\
UM & $305.20 \pm 7.37^{\mathrm{a}}$ & $161.52 \pm 11.98^{\mathrm{a}}$ & 466.72 & $65: 35: 00$ \\
\hline
\end{tabular}

Values are means $\pm \mathrm{SD}$. Values with ${ }^{\mathrm{a}-\mathrm{c}}$ different superscript within the same column are significantly different $(\mathrm{P}<0.05$; Duncan's test). HW: hot water, M: methanol, UM: ultrasonic+methanol, UHW: ultrasonic+hot water

other extractions methods. It is probably the anthocyanins could have degraded into protocatechuic acid since during heating the extract was exposed to higher temperature for a while. Hiemori et al. (2009) reported that the loss of anthocyanins in black glutinous rice may be attributed to the degradation or decomposition of anthocyanins resulting from thermal processing. And they also noticed that the content of total anthocyanins in the cooked rice were almost onethird lower than that in raw rice, whereas the levels of protocatechuic acid increased about three times after cooking. Their result indicates that Cyaniding-3glucoside in black rice degraded into protocatechuic acid during cooking which could have possibly happened with our HW treatment. However, all black glutinous rice extracts (HW, UHW, M and UM) exhibited the similar individual anthocyanin ratio dominated by $\mathrm{Cy}-3 \mathrm{G}$ followed by Pe-3-G (Table 3) relative to previous studies, where Cyaniding-3-glucoside was identified as major anthocyanin in black glutinous rice grains with peonidin-3-glucoside as the second major anthocyanin (Abdel-Aal et al., 2006). Even though composition ratio was different in our case with higher peonidin-3glucoside content corresponding to Pengkumsri et al. (2015) compared to others, where peonidin-3- glucoside contributed a very low \% (6-7\%) of anthocyanin content (Yawadio et al., 2007). The extraction procedures did not significantly affect the composition ratios of $\mathrm{Cy}-3 \mathrm{G}$ and Pe-3-G specifically in black glutinous rice. Still HW extract was able to illustrate higher $\mathrm{Cy}-3 \mathrm{G}$ ratio compared to other three black rice extracts. At the same time UM extract was able to exhibit bit higher Pe-3-G ratios compared to other extracts. The $\mathrm{Cy}-3 \mathrm{G}$ and Pe-3-G contents were significantly lower in $\mathrm{HW}$ extracts compared to other extracts while Cy-3G and Pe-3-G contents were leading in UM.

\subsubsection{Effect of extraction methods on the contents of individual flavonoid}

Quercetin and apigenin contents extracted from four extraction methods were presented in Table 4. Chromatogram of standard was shown in Figure 2. The extraction played a significant role in terms of quantification of quercetin and apigenin from two varieties of rice. Though red rice varieties are known to contain flavonoids, in our analysis, none of detectable content was achieved. Out of four extracts (black glutinous rice), UM extracts exhibited significantly higher $(\mathrm{P}<0.05)$ content of both quercetin and apigenin, almost two folds higher than UHW and M extract and six fold higher than HW extract. The present results were similar to the findings of Kim et al. (2010) where quercetin and apigenin was not detected in red and white rice varieties except in black rice variety. Especially, in HW black glutinous rice extract, lower content of quercetin was detected without the trace apigenin, illustrating the vulnerability of specific compounds with extraction techniques. Also the genetic, growing conditions and harvesting seasons might be also contributing towards differences in the specific flavonoid contents. The extraction procedures affected the extraction of flavonoids from the black rice varieties. Usually when black glutinous rice was extracted with HW, it was able to extract only quercetin, which was even significantly lower to other extraction methods. Although other extraction did not significantly affect the quercetin and apigenin ratios, its contents differed significantly $(\mathrm{P}<0.05)$ between conventional (HW and $\mathrm{M}$ extraction) and ultrasonic assisted extraction. However other extraction methods (M, UHW and UM) were able to extract both quercetin and apigenin, where UM had higher content of quercetin and apigenin compared to UHW and M extracts.

Table 4. Effect of extraction methods on Quercetin, and Apigenin and their ratios of black glutinous rice

\begin{tabular}{ccccc}
\hline \multirow{2}{*}{ Treatment } & \multicolumn{4}{c}{ Flavonoid (mg/100 g grain) } \\
\cline { 2 - 5 } & Quercetin (Q) & Apigenin (A) & Total & Q: A \\
\hline HW & $0.06 \pm 0.02^{\mathrm{c}}$ & nd & 0.06 & $100: 0$ \\
M & $0.25 \pm 0.02^{\mathrm{b}}$ & $0.027 \pm 0.01^{\mathrm{b}}$ & 0.28 & $90: 10: 00$ \\
UHW & $0.20 \pm 0.02^{\mathrm{b}}$ & $0.023 \pm 0.01^{\mathrm{b}}$ & 0.22 & $90: 10: 00$ \\
UM & $0.40 \pm 0.62^{\mathrm{a}}$ & $0.047 \pm 0.00^{\mathrm{a}}$ & 0.45 & $90: 10: 00$ \\
\hline
\end{tabular}

Values are means \pm SD. Values with ${ }^{\text {a-c }}$ different superscript within the same column are significantly different $(\mathrm{P}<0.05$; Duncan's test), and nd = not detected. HW: hot water, M: methanol, UM: ultrasonic+methanol, UHW: ultrasonic + hot water 


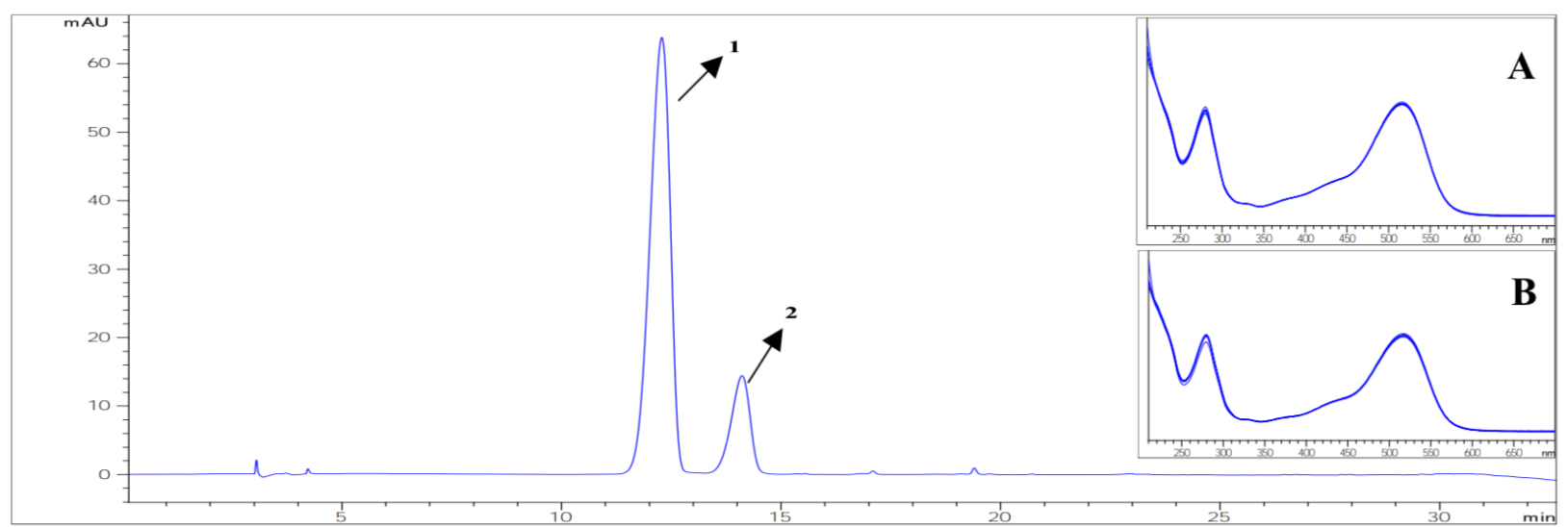

Figure 1. HPLC chromatogram of Anthocyanin standards (1, Cyaniding-3-O-glucoside; 2, peonidin-3-O-glucoside; A, Absorption spectra of Cyaniding-3-O-glucoside; B, Absorption spectra of peonidin-3-O-glucoside)

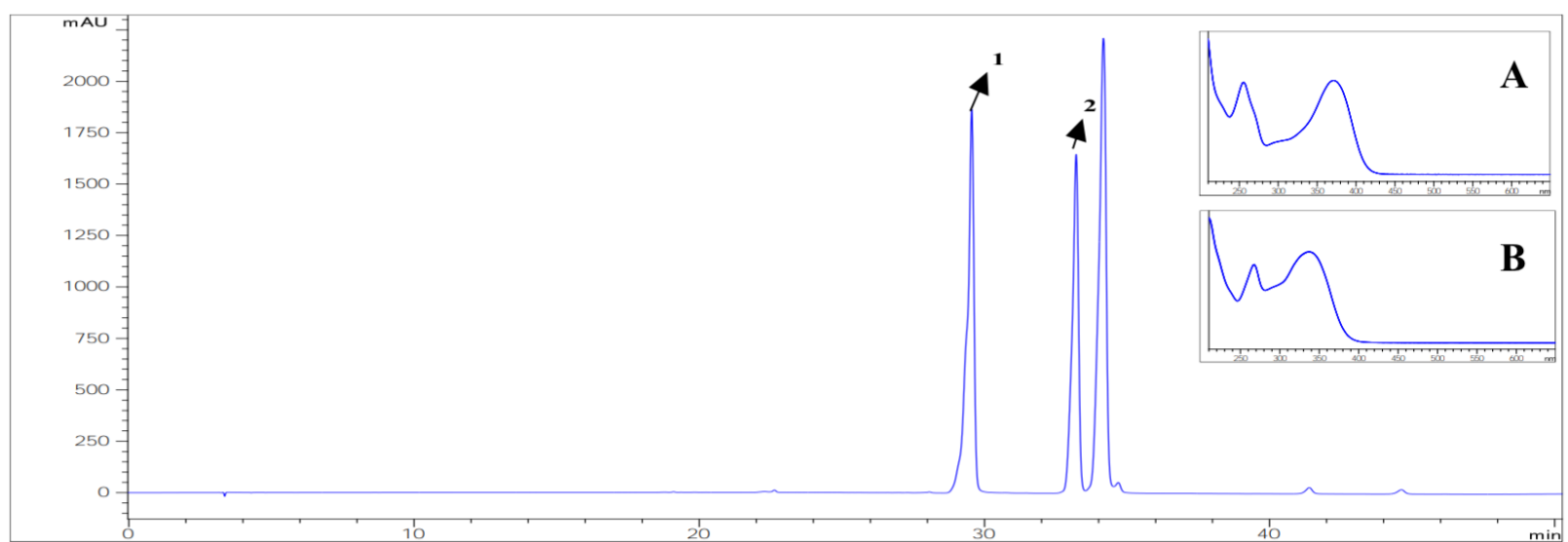

Figure 2. HPLC chromatogram of Flavonoid Standards: (1, quercetin; 2, apigenin; A, absorption spectra of Quercetin; B, absorption spectrum of Apigenin)

\section{Conclusion}

Current study showed, ultrasonic pretreatment on methanol (M) and hot water (HW) extraction from both rice varieties (black glutinous rice and red rice) significantly enhanced bioactive compounds analyzed in spectrophotometric and HPLC analysis of specific compounds of interest with potent antioxidant capabilities compared to conventional extractions alone. Ultrasonic methanol (UM) extraction proved to extract significant higher content of all the compounds analyzed in both the rice varieties. In contrast, hot water (HW) extracts exhibited lowest amount of bioactive compounds with significantly lower antioxidant activities. However, efficiency of ultrasonic pretreatment with hot water extraction was not less than methanol extraction alone.

\section{Conflict of Interest}

The authors declare no conflict of interest.

\section{Acknowledgments}

The authors would like to thank the Halal Food Science Center, Department of Food Science and Nutrition, Faculty of Science and Technology and
Graduate School Prince of Songkla University for financial support. The authors also thank the Pattani Rice Research Center, Thailand, for supplying the rice samples.

\section{References}

Abdel-Aal, E.S.M., Young, J.C. and Rabalski, I. (2006). Anthocyanin composition in black, blue, pink, purple, and red cereal grains. Journal of Agricultural and Food Chemistry, 54, 4696-4704. https:// doi.org/10.1021/jf0606609

Arab, F., Alemzadeh, I. and Maghsoudi, V. (2011). Determination of antioxidant component and activity of rice bran extract. Scientia Iranica, 18(6),14021406. https://doi.org/10.1016/j.scient.2011.09.014

Butsat, S. and Siriamornpun, S. (2010). Antioxidant capacities and phenolic compounds of the husk, bran and endosperm of Thai rice. Food Chemistry, 119 (2), 606-613. https://doi.org/10.1016/ j.foodchem.2009.07.001

Chakuton, K., Puangpronpitag, D. and Nakornriab, M. (2012). Phytochemical content and antioxidant activity of colored and non-colored Thai rice cultivars. Asian Journal of Plant Sciences, 11(6), 285-293. https://doi.org/10.3923/ajps.2012.285.293 
Cheok, C.Y., Chin, N.L., Yusof, Y.A., Talib, R.A. and Law, C.L. (2013). Optimization of total monomeric anthocyanin (TMA) and total phenolic content (TPC) extractions from mangosteen (Garcinia mangostana Linn.) hull using ultrasonic treatments. Industrial Crops and Products, 50, 1-7. https:// doi.org/10.1016/j.indcrop.2013.07.024

Chigurupati, N., Saiki, L., Gayser, C. and Dash, A.K. (2002). Evaluation of red cabbage dye as a potential natural color for pharmaceutical use. International Journal of Pharmaceutics, 241(2), 293-299. https:// doi.org/10.1016/S0378-5173(02)00246-6

Choi, Y., Jeong, H.S. and Lee, J. (2007). Antioxidant activity of methanolic extracts from some grains consumed in Korea. Food Chemistry, 103, 130-138. https://doi.org/10.1016/j.foodchem.2006.08.004

Chooklin, S. (2014). Extraction of brown rice extract and application in refined palm oil during accelerated storage. International Food Research Journal, 21(1), 291-296.

Dai, J. and Mumper, R.J. (2010). Plant Phenolics: Extraction, Analysis and Their Antioxidant and Anticancer Properties. Molecules, 15, 7313-7352. https://doi.org/10.3390/molecules 15107313

Esclapez, M.D., García-Pérez, J.V., Mulet, A. and Cárcel, J.A. (2011). Ultrasound-Assisted Extraction of Natural Products. Food Engineering Reviews, 3, 108-120. https://doi.org/10.1007/s12393-011-9036-6

Ghasemzadeh, A., Jaafar, H.Z.E., Juraimi, A.S. and Tayebi-Meigooni, A. (2015). Comparative evaluation of different extraction techniques and solvents for the assay of phytochemicals and antioxidant activity of hashemi rice bran. Molecules, 20(6), 10822-10838. https://doi.org/10.3390/ molecules200610822

Goffman, F.D. and Bergman, C.J. (2004). Rice kernel phenolic content and its relationship with antiradical efficiency. Journal of the Science of Food and Agriculture, 84(10), 1235-1240. https:// doi.org/10.1002/jsfa.1780

Golmohamadi, A., Möller, G., Powers, J. and Nindo, C. (2013). Effect of ultrasound frequency on antioxidant activity, total phenolic and anthocyanin content of red raspberry puree. Ultrasonics Sonochemistry, 20(5), 1316-1323. https:// doi.org/10.1016/j.ultsonch.2013.01.020

Goufo, P. and Trindade, H. (2014). Rice antioxidants: phenolic acids, flavonoids, anthocyanins, proanthocyanidins, tocopherols, tocotrienols, $\gamma$ oryzanol, and phytic acid. Food Science and Nutrition, 2(2), 75-104. https://doi.org/10.1002/ fsn3.86
Hiemori, M., Koh, E. and Mitchell, A.E. (2009). Influence of cooking on anthocyanins in black rice (Oryza sativa L. japonica var. SBR). Journal of Agricultural and Food Chemistry, 57, 1908-1914. https://doi.org/10.1021/jf803153z

Hossain, M.B., Brunton, N.P., Patras, A., Tiwari, B., Donnell, C.P.O., Martin-diana, A.B. and Barry-ryan, C. (2012). Optimization of ultrasound assisted extraction of antioxidant compounds from marjoram (Origanum majorana L.) using response surface methodology. Ultrasonics Sonochemistry, 19(3), 582 -590. https://doi.org/10.1016/j.ultsonch.2011.11.001

Hou, Z., Qin, P., Zhang, Y., Cui, S. and Ren, G. (2013). Identification of anthocyanins isolated from black rice (Oryza sativa L.) and their degradation kinetics. Food Research International, 50(2), 691-697. https://doi.org/10.1016/j.foodres.2011.07.037

Kapasakalidis, P.G., Rastall, R. and Gordon, M.H. (2006). Extraction of polyphenols from processed black currant (Ribes nigrum L.) residues. Journal of Agricultural and Food Chemistry, 54(11), 40164021. https://doi.org/10.1021/jf0529991

Kim, D.O. and Lee, C.Y. (2005). Extraction and Isolation of Polyphenolics. Current Protocols in Food Analytical Chemistry, 6(1), I1.2.1-I1.2.12. https://doi.org/10.1002/0471142913.fai0102s06

Kim, J.K., Lee, S.Y., Chu, S.M., Lim, S.H., Suh, S.C., Lee, Y.T. and Ha, S.H. (2010). Variation and correlation analysis of flavonoids and carotenoids in Korean pigmented rice (Oryza sativa L.) cultivars. Journal of Agricultural and Food Chemistry, 58(24), 12804-12809. https://doi.org/10.1021/jf103277g

Kim, M.K., Kim, H.A., Koh, K., Kim, H.S., Lee, Y.S. and Kim, Y.H. (2008). Identification and quantification of anthocyanin pigments in colored rice. Nutrition Research and Practice, 2(1), 46-49. https://doi.org/10.4162/nrp.2008.2.1.46

Laokuldilok, T., Shoemaker, C.F., Jongkaewwattana, S. and Tulyathan, V. (2011). Antioxidants and antioxidant activity of several pigmented rice brans. Journal of Agricultural and Food Chemistry, 59(1), 193-199. ttps://doi.org/10.1021/jf103649q

Naczk, M. and Shahidi, F. (2006). Phenolics in cereals, fruits and vegetables: Occurrence, extraction and analysis. Journal of Pharmaceutical and Biomedical Analysis, 41(5), 1523-1542. https://doi.org/10.1016/ j.jpba.2006.04.002

Paniwnyk, L., Beaufoy, E., Lorimer, J.P. and Mason, T.J. (2001). The extraction of rutin from flower buds of Sophora japonica. Ultrason Sonochemistry, 8(3), 299 -301. https://doi.org/10.1016/S1350-4177(00)000754 
Park, Y.S., Kim, S.J. and Chang, H.I. (2008). Isolation of anthocyanin from black rice (Heugjinjubyeo) and screening of its antioxidant activities. Journal of Microbiology and Biotechnology, 36(1), 55-60.

Pengkumsri, N., Chaiyasut, C., Saenjum, C., Sirilun, S., Peerajan, S., Suwannalert, P. and B.Sivamaruthi, S. (2015). Physicochemical and antioxidative properties of black, brown and red rice varieties of northern Thailand. Food Science and Technology, 35(2), 331338. https://doi.org/10.1590/1678-457X.6573

Radovanović, B. and Radovanović, A. (2010). Free radical scavenging activity and anthocyanin profile of Cabernet Sauvignon wines from the Balkan region. Molecules, 15(6), 4213-4226. https:// doi.org/10.3390/molecules 15064213

Ravanfar, R., Tamadon, A.M. and Niakousari, M. (2015). Optimization of ultrasound assisted extraction of anthocyanins from red cabbage using Taguchi design method. Journal of Food Science and Technology, 52(12), 8140-8147. https:// doi.org/10.1007/s13197-015-1880-6

Santos, D.T., Cavalcanti, R.N., Rostagno, M.S., Queiroga, C.L., Eberlin, M.N. and Meireles, A.A. (2013). Extraction of Polyphenols and Anthocyanins from the Jambul (Syzygium cumini) Fruit Peels. Food and Public Health, 3(1), 12-20. https:// doi.org/10.5923/j.fph.20130301.02

Shen, Y., Jin, L., Xiao, P., Lu, Y. and Bao, J. (2009). Total phenolics, flavonoids, antioxidant capacity in rice grain and their relations to grain color, size and weight. Journal of Cereal Science, 49(1),106-111. https://doi.org/10.1016/j.jcs.2008.07.010

Sivakumar, V., Anna, J.L., Vijayeeswarri, J. and Swaminathan, G. (2009). Ultrasound assisted enhancement in natural dye extraction from beetroot for industrial applications and natural dyeing of leather. Ultrasonic Sonochemistry, 16(6), 782-789. https://doi.org/10.1016/j.ultsonch.2009.03.009

Sun, Y., Liu, Z. and Wang, J. (2011). Ultrasoundassisted extraction of five isoflavones from Iris tectorum Maxim. Separation and Purification Technology, 78(1), 49-54. https://doi.org/10.1016/ j.seppur.2011.01.017

Wang, Q., Han, P., Zhang, M., Xia, M., Zhu, H., Ma, J. and Ling, W. (2007). Supplementation of black rice pigment fraction improves antioxidant and antiinflammatory status in patients with coronary heart disease. Asia Pacific Journal of Clinical Nutrition, 16(Suppl. 1), 295-301.

Yawadio, R., Tanimori, S. and Morita, N. (2007). Identification of phenolic compounds isolated from pigmented rice and their aldose reductase inhibitory activities. Food Chemistry, 101(4), 1616-1625. https://doi.org/10.1016/j.foodchem.2006.04.016

Zhishen, J., Mengcheng, T. and Jianming, W. (1999). The determination of Flavonoid contents in mulberry and their scavenging effects on superoxide radicals. Food Chemistry, 64(4), 555-559. https:// doi.org/10.1016/S0308-8146(98)00102-2 